\title{
Services Provided by Family Physicians for Patients With Occupational Injuries and Illnesses
}

\author{
Jong Uk Won, MD, DrPH ${ }^{1,2}$ \\ Allard E. Dembe, $S_{c} D^{2,3}$
}

${ }^{1}$ Department of Preventive Medicine, Yonsei University College of Medicine, Seoul, South Korea

${ }^{2}$ Occupational Health Program, Harvard University School of Public Health, Boston, Mass

${ }^{3}$ Department of Family Medicine and Community Health, Center for Health Policy and Research, University of Massachusetts Medical School, Worcester, Mass

Conflicts of interest: none reported

\section{CORRESPONDING AUTHOR}

Allard E. Dembe, ScD

Center for Health Policy and Research

University of Massachusetts Medical School

222 Maple Ave, Higgins Bldg

Shrewsbury, MA 01545

Allard.Dembe@umassmed.edu

\begin{abstract}
PURPOSE Many family doctors provide care to patients with occupational injuries and illnesses, but little is known about the type of medical services provided, or how they compare with services provided by other types of physicians. This study used national data to develop a statistical profile of office-based medical care delivered by family physicians to patients with work-related disorders.
\end{abstract}

METHODS Using data from 4 years (1997-2000) of the National Ambulatory Medical Care Survey, we classified visits for patients with work-related conditions according to patient and physician characteristics, services provided, and other visit characteristics. For comparison, we also compiled profiles for visits to other types of physicians for treatment of work-related disorders, and for visits to family physicians for treatment of nonoccupational conditions.

RESULTS Analyses were based on 96,183 office visits made to 4,947 physicians. A majority of visits made to family physicians for occupational conditions involved patients seeing their regular primary care doctor. Possibly for this reason, patients at these visits were more likely to have their blood pressure taken, receive diagnostic and screening services, and have prescription drugs prescribed or administered, compared with patients seeing other types of physicians. Only $73.3 \%$ of visits to family physicians for work-related disorders were expected to be paid for by workers' compensation insurance.

CONCLusions Our findings suggest that the distinctive types of care provided by family physicians to injured workers may be related to their role as the patients' regular physician. This finding is relevant to the proposals being considered by many states to expand employers' and insurers' ability to choose the treating physician in workers' compensation cases.

Ann Fam Med 2006;4:138-147. DOI: 10.1370/afm.515.

\section{INTRODUCTION}

M edical care for patients with work-related injuries and illnesses in the United States is generally governed by state workers' compensation laws. In about one half of the states, injured employees are free to choose their initial treating physician. ${ }^{1}$ Recently, many states have given employers and insurers greater control over the choice of physician, in hopes of improving care and reducing workers' compensation costs. ${ }^{2,3}$

Partly as a result, patients receiving primary care for a work-related condition often are not treated by their regular doctor. Only one quarter (25.6\%) of visits for care of work-related conditions are provided by the patient's regular primary care physician, compared with $51.2 \%$ among patients being treated for nonoccupational conditions. ${ }^{4}$ Family physicians traditionally have played an important role in providing care for patients with occupational disorders, nevertheless. Approximately $22.9 \%$ of office visits for care of work-related conditions are provided by family physicians. ${ }^{4}$ 
Little is known about the specific services that family physicians provide to patients with work-related disorders, or how they differ from the services offered by other types of physicians. This exploratory study aimed to develop a nationally representative statistical profile of the ambulatory medical care provided by family physicians to patients with work-related conditions.

\section{METHODS}

This study used data from the National Ambulatory Medical Care Survey (NAMCS), a survey of physicians providing office-based medical care in the United States. NAMCS has been conducted annually since 1973 by the US National Center for Health Statistics (NCHS). NAMCS participants included both primary care physicians and specialists providing direct patient care in office-based settings. Our analyses used information from the 1997, 1998, 1999, and 2000 NAMCS surveys, which were aggregated to yield sufficient sample sizes for a cross-sectional analysis of visits for workrelated conditions by physician type. Responses from 4,947 physicians covering 96,183 office visits were analyzed. Response rates ranged from 63\% (in 1999) to $69 \%$ (in 1997). Rates of nonresponse for individual items were generally less than $5 \% .^{5}$

NAMCS collected information on patient and physician characteristics, the clinical practice setting, reason for the visit, patients' symptoms and diagnoses, medical services provided, medications ordered or administered, and the expected source of payment for the visit. Information was provided by the treating physician or the physician's clinical staff using a written visit record form. ${ }^{5}$ Additional information regarding the clinical practice setting was obtained through personal interviews with participating physicians conducted by the US Census Bureau, on behalf of NCHS.

NAMCS used a multistage probability sampling design based on geographically related primary sampling units, physician practice characteristics within each of these units, and a systematic random sample of patient visits within each physician practice. This sampling procedure was designed to select respondents representative of those providing office-based services in various regions, practice settings, and populations throughout the United States. ${ }^{6}$

The NAMCS target population included all physician practices providing office-based patient care as classified by the American Medical Association and the American Osteopathic Association. ${ }^{5}$ NAMCS classified physicians into 15 major groupings and 129 specific types based on information supplied by the reporting physician or clinical staff, applying codes developed by the American Medical Association and the American Osteopathic
Association. The general practice category contained 4 physician subtypes: family practice (coded as FP), family practice-geriatric medicine (FPG), family practice-sports medicine (FSM), and general practice (GP).

We classified each office visit as to whether it was a visit for a work-related condition. Information collected on the patient record form allowed us to identify those visits in 2 ways: listing of workers' compensation as the primary expected source of payment for the visit, or a physician's answering yes to the question, "Was this visit related to injury or poisoning?" followed by an affirmative response to a follow-up question, "Was this injury work-related?" Of 13,191 patient visits made to family physicians, 326 involved treatment for workrelated conditions.

The basic unit of analysis for this study was the patient visit. Visit weights were calculated by the NCHS based on the sampling strata adjusted for response rates in each survey year. Descriptive statistics for patient visits from 1997 to 2000 were stratified according to whether the visit was made to a family physician for treatment of a work-related condition (FP-WR visits), a physician other than a family physician for treatment of a work-related condition (OP-WR visits), or a family physician for treatment of a non-work-related condition (FP-NWR visits). We also calculated these statistics for patient visits to occupational medicine physicians (OccMed-WR visits), to establish a comparative benchmark of how specialists in the treatment of work-related conditions care for patients. To examine how certain factors affect family physicians' care for patients with workrelated conditions, FP-WR visits were further stratified by whether care was paid for by workers' compensation insurance, the family physician was the patient's regular primary care physician, and the patient was a new patient (ie, one not seen previously by the physician).

We performed $t$ tests for continuous variables and $\chi^{2}$ tests for discrete variables to assess the statistical significance of differences between the various visit categories. Because estimates derived from our analyses were based on a sample rather than on the entire target universe of office visits, our results were subject to sampling error. To account for the complex sample design of the NAMCS, calculations were performed by the Taylor series approximation method using the SURVEYMEANS procedure in SAS software version 9.1 (SAS Institute, Cary, NC), with Strata and Cluster variables specified. ${ }^{7}$ The reported $P$ value ranges reflect this adjustment for the effect of sampling design.

\section{RESULTS}

The distribution of office visits by each of 15 major physician groupings is summarized in Table 1. Family 
physicians provided care at $22 \%$ of visits nationally for patients with work-related conditions, second only to orthopedic surgeons (33.7\% of those visits). Visits for patients with work-related conditions represented $2.5 \%$ of all office visits and thus accounted for only a small proportion of family physicians' total visit load.

Descriptive statistics for patient visits, stratified by type of visit, are summarized in Tables 2 through 4 . Table 2 shows the demographic characteristics of the patients. The majority of patients at FP-WR visits were male, white, and non-Hispanic. Patients seen for workrelated conditions, in general, were more likely to be male and to be of working age (15-64 years old) than those seen for non-work-related conditions.

The characteristics of the medical care provided for each type of physician visit are summarized in Table 3. The distribution of diagnoses for OP-WR visits was generally similar to that for FP-WR visits, involving mostly acute injuries (eg, cuts and bruises) and musculoskeletal disorders. The physician was the patient's regular primary care physician at the majority (59.2\%) of FP-WR visits. Compared with OP-WR visits, FP-WR visits were more likely to be for treatment of acute problems and to involve diagnostic and screening services, the taking of patients' blood pressure, surgical procedures, and the

\begin{tabular}{|c|c|c|}
\hline Physician Category & $\begin{array}{c}\text { Visits for } \\
\text { Work-Related } \\
\text { Conditions } \\
(n=2,387)\end{array}$ & $\begin{array}{c}\text { Visits for } \\
\text { Non-Work-Related } \\
\text { Conditions } \\
\text { (n=93,796) }\end{array}$ \\
\hline \multicolumn{3}{|l|}{ General practice } \\
\hline Family practice (FP) & 22.0 & 21.5 \\
\hline \multirow{2}{*}{$\begin{array}{l}\text { Family practice-geriatric } \\
\text { medicine (FPG) }\end{array}$} & 0.0 & 0.1 \\
\hline & 0.0 & 0.0 \\
\hline $\begin{array}{l}\text { Family practice-sports } \\
\text { medicine (FSM) }\end{array}$ & 1.0 & 3.2 \\
\hline \multicolumn{3}{|l|}{ General practice (GP) } \\
\hline Internal medicine & 8.9 & 16.6 \\
\hline Pediatrics & 0.2 & 11.7 \\
\hline General surgery & 2.4 & 2.5 \\
\hline Obstetrics and gynecology & 0.0 & 9.0 \\
\hline Orthopedic surgery & 33.7 & 4.3 \\
\hline Cardiovascular diseases & 0.1 & 2.4 \\
\hline Dermatology & 0.4 & 4.1 \\
\hline Urology & 0.1 & 2.2 \\
\hline Psychiatry & 2.8 & 3.0 \\
\hline Neurology & 2.6 & 1.0 \\
\hline Occupational medicine & 7.5 & 0.0 \\
\hline Ophthalmology & 1.1 & 6.0 \\
\hline Otolaryngology & 1.0 & 2.3 \\
\hline Other & 16.2 & 10.7 \\
\hline Total & 100.0 & 100.0 \\
\hline
\end{tabular}

administration or ordering of prescription medications. They were less likely to involve follow-up services, mental health counseling, or psychotherapy. On average, FPWR visits lasted $17 \%$ fewer minutes than OP-WR visits.

Patients seen during OccMed-WR visits had diagnoses similar to those of patients seen during FP-WR visits, but were more likely to be administered follow-up treatment, therapeutic and preventive services, injury prevention counseling, and physiotherapy. They were less likely to be treated for chronic problems than patients at FP-WR visits. FP-WR visits were considerably less likely than either OP-WR or OccMed-WR visits to be paid for by workers' compensation insurance, require insurer authorization for care, and be set up through a referral from another physician. On average, FP-WR visits were substantially shorter than either OP-WR or OccMed-WR visits.

FP-NWR visits had a diagnostic mix that differed noticeably from that of FP-WR visits and had a dissimilar patient population (eg, a greater proportion of patients who were not of working age). Consequently, the care provided at FP-WR visits differed considerably from that provided at FP-NWR visits. Despite these differences, the average time spent by family physicians for either a work-related or a non-work-related condition was approximately the same (16.1 and 16.3 minutes, respectively).

Table 4 itemizes the types of medications prescribed or administered at office visits. In general, medications were prescribed or administered to patients less often at visits for work-related conditions than at visits for non-work-related conditions. Slightly less than one half of the medications prescribed or administered at FP-WR and OP-WR visits were for pain relief, compared with $60.8 \%$ for patients seeing occupational medicine physicians. The distribution of type of medications at FP-NWR visits differed significantly from that at FP-WR visits, presumably because of the underlying differences in diagnostic and patient mix.

Among FP-WR visits, the pattern of prescribing or administering medications differed somewhat between new patients and established patients. New patients had a drug prescribed or administered at $51.9 \%$ of these visits, compared with $68.5 \%$ of visits made by patients who had seen that doctor previously $(P=.06)$.

On average, prescription medications were more likely to be ordered or administered at FPNWR visits than at other types of visits. Specifically, the mean number of medications ordered or administered was 1.39 per FP-NWR visit, compared with 0.79 per FP-WR visit, 0.68 per OccMed-WR visit, and 0.64 per OP-WR visit. 
Table 5 summarizes the characteristics of care provided during the FP-WR visits, stratified by workers' compensation payment, primary care physician status, and new patient status. Compared with visits paid for by private health insurance or other sources, visits paid for by workers' compensation insurance were more likely to require insurer authorization for care and to involve new patients. Those visits were less likely to have involved follow-up services, and the treating physician was less likely to be the patient's regular primary care physician.

When a family physician was the patient's regular primary care physician, visits were more likely to involve treatment for chronic (rather than acute) conditions and to include therapeutic and preventive services. Those visits were less likely to be paid for by workers' compensation insurance, to require insurer authorization, or to involve new patients or patients referred from other physicians. Similarly, FP-WR visits involving new patients were less likely to be made for routine chronic problems or musculoskeletal dis- orders than were visits by patients who had seen the physician previously. Those visits were more likely to involve a referral from another physician, to be paid for by workers' compensation, and to require insurer authorization for payment.

Interestingly, stratifying the FP-WR visits by workers' compensation payment, new patient status, and primary care physician status had little effect on the distribution of services provided during the visit. The only difference was a slightly greater likelihood among patients seeing their regular primary care doctor to receive therapeutic and preventive services. Otherwise, no significant differences between visit categories were observed with respect to the types of services provided.

\section{DISCUSSION}

This exploratory study has produced a profile of medical care visits provided by family physicians for patients with work-related injuries and illnesses. To the best of our knowledge, this is the nation's first study focusing specifically on the types of medical care and services provided by family physicians to injured workers. The use of nationally representative NAMCS data allowed us to describe these visits according to key patient and medical care characteristics.

Our data indicate that family physicians play a leading role in treating injured workers in the United States, delivering nearly one quarter of the office visits for patients with workrelated injuries and illnesses. Family physicians provide approximately 3 times as many visits each year to injured workers as do occupational medicine specialists. Because only a small proportion $(2.5 \%)$ of office visits are made by patients with workrelated conditions, however, many family physicians may not be aware of their substantial contribution to the care of America's injured workers.

Our study found that the majority (59.2\%) of patients with work-related conditions who see a family physician are receiving care from their regular primary care doctor, compared with only $13.1 \%$ of injured workers seen by other types of physicians. One reason is that many injured workers are treated by specialists, such as orthopedic surgeons and occupational medi- 
Table 3. Medical Care Characteristics, Percentage of Office Visits, NAMCS Data, 1997-2000

\begin{tabular}{|c|c|c|c|c|}
\hline \multirow[b]{2}{*}{ Medical Care Characteristic } & \multicolumn{4}{|c|}{ Visit Type } \\
\hline & $\begin{array}{l}\text { FP-WR* } \\
(\mathrm{n}=326)\end{array}$ & $\begin{array}{c}\text { OP-WR } \\
(\mathrm{n}=2,061)\end{array}$ & $\begin{array}{l}\text { OccMed-WR } \\
(\mathrm{n}=180)\end{array}$ & $\begin{array}{c}\text { FP-NWR } \\
(n=12,865)\end{array}$ \\
\hline \multicolumn{5}{|l|}{ Major reason for visit } \\
\hline Acute problem & 55.3 & $35.4^{\S}$ & 48.5 & $48.4^{+}$ \\
\hline Chronic problem, routine & 16.9 & 20.7 & $7.1^{\S}$ & $22.7^{+}$ \\
\hline Chronic problem, flare-up & 10.5 & 9.1 & $5.4^{\ddagger}$ & 8.7 \\
\hline Presurgery or postsurgery/injury follow-up & 12.2 & $30.4^{\S}$ & $36.1^{\S}$ & $2.4 \S$ \\
\hline $\begin{array}{l}\text { Non-illness (eg, routine prenatal, general examination, } \\
\text { well-baby) }\end{array}$ & 3.5 & 2.1 & 1.8 & $16.1^{\ddagger}$ \\
\hline \multicolumn{5}{|l|}{ Patient's chief complaints and symptoms } \\
\hline Musculoskeletal symptoms & 46.5 & 50.7 & 50.8 & $10.3^{\S}$ \\
\hline Injury or poisoning & 28.5 & $16.0^{\S}$ & 25.3 & $2.7 \S$ \\
\hline \multicolumn{5}{|l|}{ Physician's diagnosis of patient's condition (ICD-9 groupings) } \\
\hline Infectious and parasitic diseases & 0.1 & 0.2 & 0.0 & $3.5^{\S}$ \\
\hline Neoplasm & 0.0 & 0.1 & 0.0 & 1.2 \\
\hline Endocrine, nutritional, metabolic, and immune disorders & 0.0 & 0.2 & 0.0 & $7.3 \S$ \\
\hline Mental disorders & 1.1 & $4.0^{\S}$ & 1.0 & $3.8^{\S}$ \\
\hline Diseases of nervous system, sense organs & 5.5 & 6.7 & $2.7^{\ddagger}$ & 5.7 \\
\hline Diseases of circulatory system & 1.5 & $0.5^{+}$ & 0.0 & $9.6^{\S}$ \\
\hline Diseases of respiratory system & 1.7 & $0.5^{\ddagger}$ & 0.0 & $19.4^{\S}$ \\
\hline Diseases of digestive system & 0.6 & 1.3 & 0.8 & $3.9^{+}$ \\
\hline Diseases of genitourinary system & 0.5 & 0.1 & 0.0 & $4.7^{\ddagger}$ \\
\hline Diseases of skin, subcutaneous tissue, hair, nails & 1.2 & 1.2 & 0.0 & $4.4 \S$ \\
\hline Diseases of musculoskeletal system, connective tissue & 25.3 & 28.9 & 28.5 & $8.0^{\S}$ \\
\hline Symptoms, signs, and ill-defined conditions & 1.8 & 2.5 & 2.0 & $7.1^{\S}$ \\
\hline Injury and poisoning & 54.0 & $43.9^{\ddagger}$ & 58.8 & $6.4^{\S}$ \\
\hline Supplementary classification and other diagnoses & 6.1 & 9.8 & 5.4 & $14.1^{\dagger}$ \\
\hline Visit was related to a specific injury or poisoning & 94.1 & 89.4 & 95.2 & $10.2^{\S}$ \\
\hline Visit was related to a self-inflicted injury or poisoning & 0.0 & 0.4 & 0.0 & 0.0 \\
\hline Patient's condition resulted from an assault & 2.4 & 2.1 & $1.3^{+}$ & $0.1^{\S}$ \\
\hline \multicolumn{5}{|l|}{ Services provided during visit } \\
\hline Diagnostic and screening services & 72.2 & $56.6 \S$ & 74.3 & $80.8^{\ddagger}$ \\
\hline Blood pressure reading & 57.2 & $24.2^{\S}$ & 54.6 & $66.7^{\dagger}$ \\
\hline Radiograph & 20.0 & 21.2 & 21.8 & $6.3^{\S}$ \\
\hline Therapeutic and preventive services & 46.0 & 50.3 & $68.7 \S$ & $36.7^{\dagger}$ \\
\hline Exercise counseling and education & 14.9 & 14.2 & 14.9 & 13.1 \\
\hline Injury prevention counseling and education & 15.4 & 13.5 & $43.5^{\S}$ & $2.9^{\S}$ \\
\hline Mental health counseling and education & 0.8 & $2.1^{\dagger}$ & 0.0 & $2.4 \S$ \\
\hline Surgical procedures & 4.5 & $2.6^{\ddagger}$ & 2.6 & 2.6 \\
\hline \multicolumn{5}{|l|}{ Therapy provided during visit } \\
\hline Physiotherapy & 19.6 & 23.6 & $32.7^{\ddagger}$ & $2.5^{\S}$ \\
\hline Psychotherapy & 0.0 & $3.6^{\S}$ & $1.3^{+}$ & 0.7 \\
\hline Psychopharmacotherapy & 0.3 & $3.2^{\ddagger}$ & 0.0 & 0.5 \\
\hline At least 1 drug was prescribed during the visit & 65.2 & $46.7 \S$ & 52.8 & $76.3 \S$ \\
\hline \multicolumn{5}{|l|}{ Medical professionals seen during the visit } \\
\hline Physician & 96.3 & 96.8 & 94.2 & 95.1 \\
\hline Physician assistant & 1.0 & $2.7^{\dagger}$ & $0.1^{\S}$ & 1.7 \\
\hline Nurse-practitioner & 2.1 & $0.5^{\ddagger}$ & 0.0 & 1.8 \\
\hline Nurse-midwife & 0.0 & 0.1 & 0.3 & 0.1 \\
\hline RN & 19.8 & $7.5^{\S}$ & $8.7^{\ddagger}$ & 16.1 \\
\hline LPN & 20.1 & $6.4 \S$ & $0.0 \S$ & 18.6 \\
\hline Medical/nursing assistant & 23.2 & $15.6 \S$ & 17.9 & 25.6 \\
\hline Other & 1.9 & $5.6^{\S}$ & $5.3^{\dagger}$ & 3.0 \\
\hline \multirow[t]{2}{*}{ Physician was patient's regular primary care physician } & 59.2 & $13.1^{\S}$ & $7.9^{\S}$ & $84.8^{\S}$ \\
\hline & & & & Table 3 continues \\
\hline
\end{tabular}


Table 3. continued

\begin{tabular}{|c|c|c|c|c|}
\hline \multirow[b]{2}{*}{ Medical Care Characteristic } & \multicolumn{4}{|c|}{ Visit Type } \\
\hline & $\begin{array}{c}\text { FP-WR* } \\
(n=326)\end{array}$ & $\begin{array}{c}\text { OP-WR } \\
(n=2,061)\end{array}$ & $\begin{array}{c}\text { OccMed-WR } \\
(n=180)\end{array}$ & $\begin{array}{c}\text { FP-NWR } \\
(n=12,865)\end{array}$ \\
\hline \multicolumn{5}{|l|}{ Primary expected source of payment for the visit } \\
\hline Private insurance & 16.3 & $10.3 \S$ & $0.7 \S$ & $58.3 \S$ \\
\hline Medicare & 2.0 & 2.0 & 0.0 & $17.3 \S$ \\
\hline Medicaid & 3.0 & $0.3 \S$ & $0.0^{+}$ & $9.3^{\S}$ \\
\hline Self-pay & 2.4 & $1.0^{+}$ & $0.3^{\ddagger}$ & $7.0^{\ddagger}$ \\
\hline Workers' compensation & 73.3 & $83.4^{\ddagger}$ & $93.8^{\S}$ & $0.0 \S$ \\
\hline No charge & 0.7 & 0.1 & 0.0 & 0.3 \\
\hline Other & 1.1 & 2.1 & $5.3^{\S}$ & $5.3^{\S}$ \\
\hline Unknown & 0.5 & 0.5 & 0.0 & 1.8 \\
\hline Care was provided in an $\mathrm{HMO}$ setting & 15.9 & $10.2^{\ddagger}$ & 10.7 & $31.0^{\S}$ \\
\hline Capitated payment basis for the visit & 7.2 & 4.2 & 6.2 & $16.9^{\ddagger}$ \\
\hline Patient was a new patient & 19.7 & 22.1 & 26.5 & $8.0^{\S}$ \\
\hline Patient was referred by another physician/health plan & 9.6 & $31.5^{\S}$ & $21.1^{\dagger}$ & $3.3^{\ddagger}$ \\
\hline Authorization from insurer was required for care & 19.6 & $40.4 \S$ & $47.0^{\S}$ & $3.2^{\S}$ \\
\hline Time spent with physician, mean, min & 16.1 & $19.4 \S$ & $22.0 \S$ & 16.3 \\
\hline \multicolumn{5}{|c|}{$\begin{array}{l}\text { NAMCS = National Ambulatory Medical Care Survey; ICD-9 = International Classification of Diseases, Ninth Revision; FP-WR = visit to family practice physician for work-related } \\
\text { condition; OP-WR = visit to non-family practice physician for work-related condition; OccMed-WR = visit to occupational medicine physician for work-related condition; FP- } \\
\text { NWR = visit to family practice physician for non-work-related condition; RN = registered nurse; LPN = licensed practical nurse; HMO = health maintenance organization. } \\
\text { * Reference category for comparison. } \\
\dagger P<.05 \\
\ddagger P<.01 \\
\S P<.001\end{array}$} \\
\hline
\end{tabular}

Table 4. Weighted Percentage Distributions of Medications Prescribed or Administered During Office Visits, by Category, NAMCS Data, 1997-2000

\begin{tabular}{lcccc}
\hline & \multicolumn{3}{c}{ Visit Type } \\
\cline { 2 - 5 } Medications Category & FP-WR * & OP-WR & OccMed-WR & FP-NWR \\
\hline Anesthetics & 2.0 & 1.4 & 1.5 & $0.6^{\ddagger}$ \\
Antimicrobials & 4.3 & 3.5 & 1.1 & $13.2^{\S}$ \\
Hematologic agents & 0.3 & 0.5 & 0.0 & $1.6^{\dagger}$ \\
Cardiovascular-renal drugs & 6.4 & $3.4^{\dagger}$ & $0.0^{\ddagger}$ & $16.2^{\S}$ \\
Central nervous system drugs & 8.4 & $12.5^{\ddagger}$ & $2.3^{\ddagger}$ & 8.1 \\
Contrast media/radiopharmaceuticals & 0.0 & 0.1 & 0.0 & 0.3 \\
Gastrointestinal agents & 1.1 & 1.1 & 0.0 & $4.5^{\S}$ \\
Metabolic agents/nutrients & 0.9 & 0.8 & 0.3 & $5.8^{\S}$ \\
Hormones/hormonal mechanisms & 4.8 & 4.4 & 1.7 & $10.4^{\S}$ \\
Immunologics & 1.5 & 1.3 & $5.2^{\dagger}$ & $3.5^{\dagger}$ \\
Skin/mucous membrane agents & 5.0 & 5.2 & 9.1 & 4.3 \\
Neurologic drugs & 11.4 & 10.6 & 12.0 & $2.1^{\S}$ \\
Oncolytics & 0.0 & 0.2 & 0.0 & 0.1 \\
Ophthalmics & 0.4 & $2.4 \dagger$ & $4.0^{\ddagger}$ & 0.7 \\
Otologics & 0.2 & 0.2 & 0.0 & 0.9 \\
Analgesics & 48.6 & 47.1 & $60.8^{\ddagger}$ & $11.8^{\S}$ \\
Antiparasitics & 0.0 & 0.3 & 0.0 & 0.3 \\
Respiratory tract agents & 2.6 & 3.5 & 1.8 & $12.9^{\S}$ \\
Unclassified/miscellaneous & 1.9 & 1.2 & 0.3 & 2.7 \\
Homeopathic products & 0.3 & 0.1 & 0.0 & 0.1 \\
Total & 100.0 & 100.0 & 100.0 & 100.0 \\
Total no. prescribed/ordered & 317 & 1,347 & 122 & 17,883 \\
\hline
\end{tabular}

NAMCS = National Ambulatory Medical Care Survey; FP-WR = visit to family practice physician for work-related condition; OP-WR = visit to non-family practice physician for work-related condition; OccMed-WR = visits to occupational medicine physician for work-related condition; FP-NWR = visit to family practice physician for non-work-related condition.

* Reference category for comparison.

$+P<.05$

$\neq P<.01$

$\S P<.001$ cine physicians. Also, many states now allow employers and insurers to choose the treating physician in workers' compensation cases, making it less likely that a patient will see his or her regular primary care physician. Recently, many states have expanded employers' and insurers' control over the choice of physician in workers' compensation cases, in hopes of thereby constraining costs. ${ }^{1-3}$ Worker and advocacy groups have expressed concerns about this trend, believing that it detracts from effective coordination and continuity of care, and could jeopardize the quality of care by directing patients to physicians who will inappropriately limit patient services in response to employer and insurer interests. ${ }^{7-9}$

Our study's findings may be relevant in this regard. 
Table 5. Medical Care Characteristics by Selected Visit Characteristics, Percentage of Office Visits to Family Physicians for Treatment of Work-Related Conditions (N = 326 Visits), NAMCS Data, 1997-2000

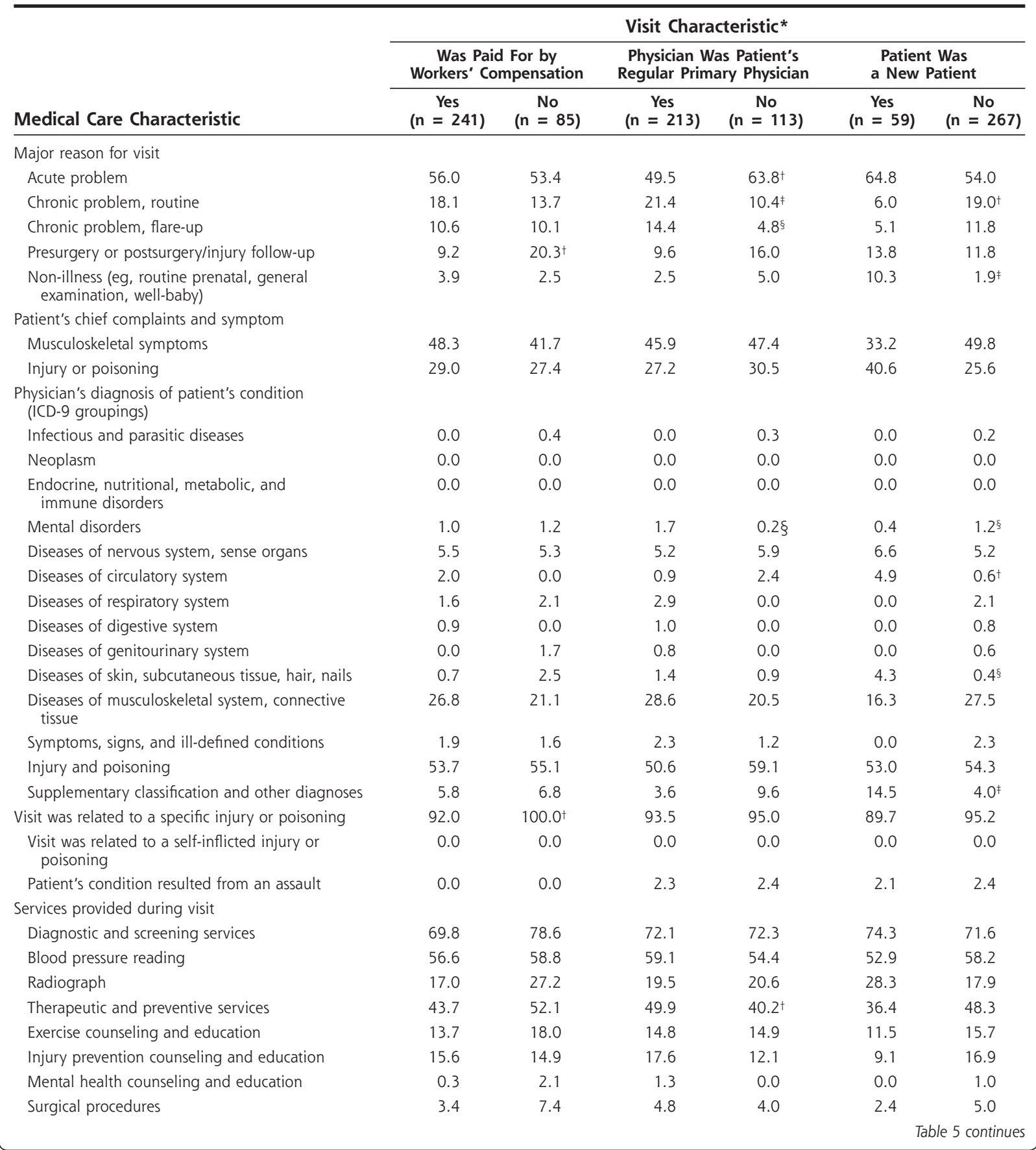

For example, patients with work-related conditions visiting family physicians were more than twice as likely to have their blood pressure measured during a visit than were patients seeing other types of physicians ( $57.2 \%$ vs $24.2 \%)$. When the family physician was also the patient's primary care physician, that proportion was even higher (59.1\%). Similarly, injured workers seeing a family physician were $27.6 \%$ more likely to receive diagnostic and screening services, and 39.6\% more likely to have a drug administered or prescribed compared with patients seeing other types of physicians. This pattern suggests that family physicians care for patients with work-related conditions in a broader context than do physicians who merely see a patient 


\begin{tabular}{|c|c|c|c|c|c|c|}
\hline \multirow[b]{3}{*}{ Medical Care Characteristic } & \multicolumn{6}{|c|}{ Visit Characteristic* } \\
\hline & \multicolumn{2}{|c|}{$\begin{array}{c}\text { Was Paid For by } \\
\text { Workers' Compensation }\end{array}$} & \multicolumn{2}{|c|}{$\begin{array}{l}\text { Physician Was Patient's } \\
\text { Regular Primary Physician }\end{array}$} & \multicolumn{2}{|c|}{$\begin{array}{l}\text { Patient Was } \\
\text { a New Patient }\end{array}$} \\
\hline & $\begin{array}{c}\text { Yes } \\
(n=241)\end{array}$ & $\begin{array}{l}\text { No } \\
(n=85)\end{array}$ & $\begin{array}{c}\text { Yes } \\
(n=213)\end{array}$ & $\begin{array}{c}\text { No } \\
(\mathrm{n}=113)\end{array}$ & $\begin{array}{c}\text { Yes } \\
(n=59)\end{array}$ & $\begin{array}{c}\text { No } \\
(n=267)\end{array}$ \\
\hline \multicolumn{7}{|l|}{ Therapy provided during visit } \\
\hline Physiotherapy & 18.4 & 22.8 & 22.9 & 14.9 & 12.7 & 21.3 \\
\hline Psychotherapy & 0.0 & 0.0 & 0.0 & 0.0 & 0.0 & 0.0 \\
\hline Psychopharmacotherapy & 0.3 & 0.0 & 0.4 & 0.0 & 0.0 & 0.3 \\
\hline At least 1 drug was prescribed during the visit & 63.3 & 70.4 & 65.9 & 64.2 & 51.9 & 68.5 \\
\hline \multicolumn{7}{|l|}{ Medical professionals seen during the visit } \\
\hline Physician & 95.9 & 97.3 & 97.7 & 94.2 & 92.1 & 97.3 \\
\hline Physician assistant & 0.5 & 2.5 & 1.5 & 0.3 & 0.6 & 1.1 \\
\hline Nurse-practitioner & 2.9 & 0.0 & 1.4 & 3.2 & 6.5 & 1.0 \\
\hline Nurse-midwife & 0.0 & 0.0 & 0.0 & 0.0 & 0.0 & 0.0 \\
\hline RN & 21.5 & 15.3 & 17.5 & 23.3 & 18.6 & 20.1 \\
\hline LPN & 19.1 & 22.8 & 20.1 & 20.0 & 18.7 & 20.4 \\
\hline Medical/nursing assistant & 23.1 & 23.6 & 24.3 & 21.6 & 23.9 & 23.0 \\
\hline Other & 2.1 & 1.3 & 1.9 & 2.0 & 4.9 & $1.2^{\ddagger}$ \\
\hline $\begin{array}{l}\text { Physician was patient's regular primary care } \\
\text { physician }\end{array}$ & 52.7 & $77.1^{\S}$ & 100.0 & 0.0 & 18.0 & $69.4 \S$ \\
\hline \multicolumn{7}{|l|}{ Primary expected source of payment for the visit } \\
\hline Private insurance & 0.0 & 61.0 & 23.9 & $5.2^{\S}$ & 4.9 & $19.1^{\S}$ \\
\hline Medicare & 0.0 & 7.5 & 3.4 & $0.0^{+}$ & 0.0 & 2.5 \\
\hline Medicaid & 0.0 & 11.2 & 4.0 & 1.5 & 1.4 & 3.4 \\
\hline Self-pay & 0.0 & 9.1 & 1.2 & 4.2 & 4.6 & 1.9 \\
\hline Workers' compensation & 100.0 & 0.0 & 65.2 & $85.0^{\S}$ & 89.1 & $69.4^{\S}$ \\
\hline No charge & 0.0 & 2.5 & 0.0 & 1.6 & 0.0 & 0.8 \\
\hline Other & 0.0 & 4.1 & 1.8 & 0.0 & 0.0 & 1.4 \\
\hline Unknown & 0.0 & 1.9 & 0.0 & 1.3 & 0.0 & $17.9^{\S}$ \\
\hline Care was provided in an $\mathrm{HMO}$ setting & 10.2 & $31.5^{\S}$ & 23.3 & $5.1^{\S}$ & 7.7 & 7.7 \\
\hline Capitated payment basis for the visit & 4.9 & $13.7 \S$ & 8.4 & 5.5 & 5.4 & $0.0 \S$ \\
\hline Patient was a new patient & 24.0 & $8.0^{\ddagger}$ & 6.0 & $39.7 \S$ & 100.0 & 0.0 \\
\hline $\begin{array}{l}\text { Patient was referred by another physician/health } \\
\text { plan }\end{array}$ & 11.1 & 5.5 & 4.4 & $17.1^{\S}$ & 21.9 & $6.6^{\ddagger}$ \\
\hline Authorization from insurer was required for care & 24.8 & $5.5^{\S}$ & 16.0 & $24.0^{+}$ & 28.9 & 17.4 \\
\hline Time spent with physician, mean, min & 16.1 & 15.9 & 16.8 & 14.9 & 13.6 & 16.7 \\
\hline \multicolumn{7}{|c|}{$\begin{array}{l}\text { NAMCS = National Ambulatory Medical Care Survey; ICD-9 = International Classification of Diseases, Ninth Revision; FP-WR }=\text { visit to family physician for work-related condi- } \\
\text { tion; OP-WR = visit to non-family physician for work-related condition; OccMed-WR }=\text { visit to occupational physician for work-related condition; FP-NWR = visit to family } \\
\text { physician for non-work-related condition; RN = registered nurse; } \mathrm{LPN}=\text { licensed practical nurse; } \mathrm{HMO}=\text { health maintenance organization. }\end{array}$} \\
\hline $\begin{array}{l}\text { * Comparisons were between No column and correspondi } \\
\dagger P<.05 \\
\text { † } P<.01 \\
\S P<.001\end{array}$ & column. & & & & & \\
\hline
\end{tabular}

on a single occasion for a discrete work-related injury. Family physicians may be more apt to view the patient as a whole person, to be aware of comorbidities and the patient's history, and thus to use these visits as an opportunity for assessing and caring for the individual's overall health, compared with physicians who have a narrower focus restricted to treating a specific work-related injury.

In this respect, it is interesting that there were no significant differences between family physicians and other types of physicians in the delivery of therapeutic and preventive services, exercise counseling and educa- tion, injury prevention counseling and education, and physiotherapy services to injured workers. Perhaps family physicians give comparable emphasis (as other physicians) to treating the specific work-related injury, but additionally place greater emphasis on general health screening and diagnosis during the visit. Similarly, it is conceivable that family physicians' greater tendency to prescribe or administer drugs during the visit reflects their attention to their patients' comorbidities and the need for their "regular" patients to have prescriptions refilled while at the office. Indeed, new patients seeing 
family physicians for treatment of a work-related condition had a drug prescribed or administered at $51.9 \%$ of visits, compared with $68.5 \%$ of visits among patients who had seen that doctor previously.

Only $73.3 \%$ of FP-WR visits were expected to be paid for by workers' compensation, compared with $83.4 \%$ of visits to other types of physicians and $93.8 \%$ of those to occupational medicine physicians. These findings are consistent with other studies indicating that many legitimate cases of work-related conditions are not reported to workers' compensation insurers and thus are not reflected adequately in data based on workers' compensation claims filings. ${ }^{10-13}$ It has been estimated that $10 \%$ to $40 \%$ of cases are not reported. Suggested reasons for underreporting include fear of reprisal from employers, lack of knowledge about how to file claims, physicians' failure to correctly identify work-relatedness, and inappropriate denial of claims by workers' compensation insurers. The differences in workers' compensation payment observed in this study between family physicians and other types of physicians may indicate that patients seeing their regular primary care doctor are more likely to seek payment through conventional private or public health insurance than to try to secure coverage and reimbursement from the employer's workers' compensation insurer. Although potentially expedient for both patient and doctor, this practice should be discouraged for several reasons: (1) the resulting underestimation of occupational injuries detracts from the usefulness of workers' compensation data for surveillance and prevention, (2) this practice could make it more difficult for the worker to obtain wage replacement and other workers' compensation benefits, (3) it may necessitate patient copayments or other out-of-pocket expenses that would otherwise be covered by workers' compensation, and (4) physicians might be less likely to provide prevention, return-towork, and impairment determination services that are normally covered in workers' compensation cases.

Our comparison of the care provided by family physicians with that provided by occupational medicine specialists suggests that there are ways in which family physicians can enhance their services for injured workers. For example, compared with family physicians, occupational medicine specialists were nearly 3 times more likely to provide injured workers with injury prevention counseling and education. Interestingly, family physicians were equally as likely as occupational medicine specialists to provide their patients with exercise counseling and education. This finding suggests that family physicians caring for injured workers might need additional training and familiarity with effective injury prevention techniques that can be used by the patient or suggested by the patient to the employer. Several commentators have noted the barriers doctors face in incorporating injury prevention counseling into primary medical care. ${ }^{14-17}$ Providing injury prevention advice is an important goal, however, especially for patients with work-related disorders who may continue to face injury hazards when they return to their jobs.

Our results suggest that family physicians often use a patient's visit for a work-related condition as an opportunity to assess the patient's overall health and provide care for other nonoccupational comorbidities. In theory, combining both types of services in a single visit could enhance continuity of care and improve the quality of care for work-related conditions, for example, through better understanding of the relationship between the patient's underlying medical condition and their work-related disorder, and by identifying potentially dangerous drug interactions. Additional research is needed to examine this issue thoroughly and to assess its implications for states' efforts to control injured workers' choice of physicians and limit their ability to see their regular family doctor.

Another topic for additional research suggested by this preliminary study is whether providing injury prevention counseling and education to the injured worker during the visit affects the type of medical services delivered, the likelihood of follow-up visits, and eventual patient outcomes, such as recovery of vocational function and reduction of pain. Some of these questions could be investigated by further analysis of the NAMCS data, for example, the relationship between providing injury prevention counseling during the visit and the delivery of medications, physiotherapy, and other services during the visit. Using NAMCS data, it would also be possible to examine the effect of providing counseling on the length of visit. We suspect that providing injury prevention counseling would reduce the need for certain other medical services (eg, physiotherapy) while only slightly lengthening visit duration.

Other data sources would be needed to examine longer-term follow-up issues, such as the relationship between injury prevention counseling and the likelihood of return visits or additional therapeutic services. Ideally, it would be useful to investigate the extent to which the delivery of particular services (blood pressure monitoring, injury prevention counseling, prescription drug use) is related to physician type, diagnosis, practice characteristics, workers' compensation status, geographical region, and patient characteristics (sex, age, race/ethnicity). It would also be desirable to analyze the relationship between the observed patterns of care and long-term patient outcomes, including functional recovery, return to work, costs, and patients' experience with care. In this preliminary study, we did 
not have access to potentially important information that would be relevant, such as the patient's employment status, occupation, and general health status; the mechanism of injury; the severity of the patient's condition; costs of care; or the patient's eventual functional and vocational outcomes.

Our exploratory analysis had other limitations. It was based on self-reported information from physicians and clinical staff, and thus was subject to possible reporting errors or omissions. There was no way to independently verify the data contained in NAMCS. Special training provided to participating physicians by NCHS about how to complete the survey forms presumably helped mitigate such potential errors.

The data compiled in this preliminary study will be useful for establishing benchmarks to help family physicians assess the extent and type of services currently provided for work-related conditions, relative to national norms. The data should help state workers' compensation officials better understand family physicians' role in caring for injured workers. Additionally, the study highlights gaps in knowledge that can be addressed through additional research. The goal of research in this area is to identify ways of improving care for workers with occupational injury, to deliver care in an efficient manner, and, ultimately, to promote better overall health outcomes for patients.

To read or post commentaries in response to this article, see it online at http://www.annfammed.org/cgi/content/full/4/2/138.

Key words: Family practice; occupational health; occupational diseases; work; employment; workers' compensation; National Ambulatory Medical Care Survey

Submitted May 6, 2005; submitted, revised, October 12, 2005; accepted October 24, 2005.

Funding support: This study received funding support through grant T42-CCT122961-02 from the US Centers for Disease Control and Prevention/NIOSH.

Acknowledgments: The authors are grateful to the comments and suggestions made by Steve Banks, Judy Savageau, Sharon Fox, Robin Clark, and Ann Lawthers.

\section{References}

1. Tanabe RP, Murray S. Managed Care and Medical Cost Containment in Workers' Compensation: A National Inventory, 2001-2002. Cambridge, Mass: Workers' Compensation Research Institute; 2004.

2. Boden LI, Ruser JW. Workers compensation "reforms," choice of medical care provider, and reported workplace injuries. Rev Econ Statistics. 2003;85:923-929.

3. D'Andrea DC, Meyer JD. Workers' compensation reform. Clin Occup Environ Med. 2004;4:259-271.

4. Dembe AE, Savageau JA, Amick BC 3rd, Banks SM. Office-based medical care for work-related conditions: findings from the National Ambulatory Medical Care Survey, 1997-1998. J Occup Environ Med. 2002;44:1106-1117.

5. Cherry DK, Woodwell DA. National Ambulatory Medical Care Survey: 2000 Summary. Advance Data From Vital and Health Statistics, No. 328. Hyattsville, Md: National Center for Health Statistics; 2002.

6. Bryant E, Shimizu I. Sample design, sampling variance, and estimation procedures for the National Ambulatory Medical Care Survey. Vital Health Stat 2. 1988:1-39. Available at: http://www.cdc.gov/nchs/ about/major/ahcd/ahcd1.htm. Accessed October 11, 2005.

7. Ellenberger JN. The battle over workers' compensation. New Solutions. 2000; 10:217-236.

8. Reville RT, Escarce JJ. Managed care and the workers' compensation bargain. Med Care. 1999;37:969-971.

9. Dembe AE. Preserving workers' compensation benefits in a managed health care environment. J Public Health Policy. 1998;19:200-218.

10. Azaroff LS, Levenstein C, Wegman DH. Occupational injury and illness surveillance: conceptual filters explain underreporting. Am J Public Health. 2002;92:1421-1429.

11. Shannon HS, Lowe GS. How many injured workers do not file claims for workers' compensation benefits? Am J Ind Med. 2002;42:467-473.

12. Beardwood BA, Kirsh B, Clark NJ. Victims twice over: perceptions and experiences of injured workers. Qual Health Res. 2005;15:30-48.

13. Pransky G, Snyder T, Dembe A, Himmelstein J. Under-reporting of work-related disorders in the workplace: a case study and review of the literature. Ergonomics. 1999;42:171-182.

14. Knight S, Guenther E, Olson L. Injury prevention counseling in visits to office-based physicians in the United States. Poster presented at: 131st Annual Meeting of the American Public Health Association; November 17, 2003; San Francisco, Calif.

15. Hensrud DD. Clinical preventive medicine in primary care. Background and practice: 1 . Rationale and current preventive practices. Mayo Clin Proc. 2000;75:165-172.

16. Mirand AL, Beehler GP, Kuo CL, Mahoney MC. Explaining the de-prioritization of primary prevention: physicians' perceptions of their role in the delivery of primary care. BMC Public Health. 2003;3:15.

17. Yarnall KS, Pollak KI, Ostbye T, Krause KM, Michener JL. Primary care: is there enough time for prevention? Am J Public Health. 2003;93:635-641. 